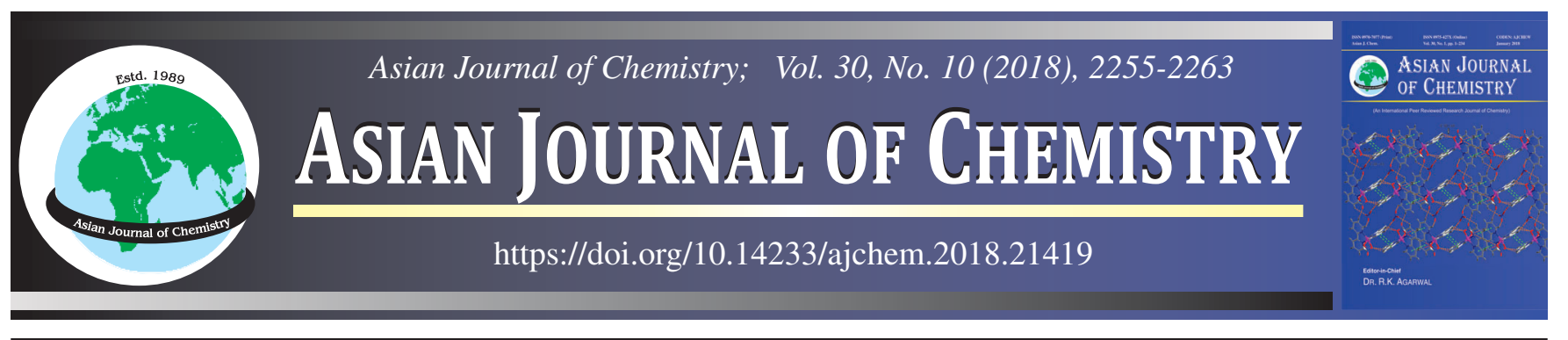

\title{
Simulation of Structure, Molecular Orbitals, Electron Density and Reactivity Aspects of Rubber Vulcanization Accelerator 2-Mercaptobenzothiazole by Density Functional Theory
}

\section{V.K. ViJaYAn ${ }^{1}$, E. PURushothaman ${ }^{1}$, V. ArJunan ${ }^{2,3, *}$ and S. Mohan ${ }^{4}$}

${ }^{1}$ Department of Chemistry, University of Calicut, Calicut-673 635, India

${ }^{2}$ Department of Chemistry, Kanchi Mamuniavr Centre for Post-Graduate Studies, Puducherry-605 008, India

${ }^{3}$ Rajiv Gandhi Arts \& Science College, Thavalakuppam, Puducherry-605 007, India

${ }^{4}$ School of Sciences and Humanities, Vel Tech University, Avadi, Chennai-600 062, India

*Corresponding author: E-mail: varjunftir@yahoo.com; varjun.ftir@gmail.com

Received: 3 May 2018;

Accepted: 13 June 2018;

Published online: 31 August 2018;

AJC-19053

\begin{abstract}
In this study, insights on the charge transfer and reactivity properties of 2-mercaptobenzothiazole are presented. The structural parameters are determined by B3LYP method. Delocalization of the lone pair electrons of S3 towards N1=C2 is possible and thereby decreases in force constant and increase in C2-S3 bond length than C2-S14. The C8-C9 bond distance increases due to the electron withdrawing nature of nitrogen. Negative electrostatic potentials reside on nitrogen whereas positive electrostatic potentials lie on hydrogen in S-H group. The LUMO-HOMO energy gap determines the charge transfer capacity and is equal to $5.1370 \mathrm{eV}$. The $\mathrm{n}_{\mathrm{S}} \rightarrow \pi^{*}{ }_{\mathrm{NC}}$ interaction between the sulphur (S3) lone pair and the N1=C2 antibonding orbital gives strong stabilization by $26.70 \mathrm{kcal}^{\mathrm{mol}}{ }^{-1}$. The $\mathrm{n}_{\mathrm{S}} \rightarrow \pi^{*}{ }_{\mathrm{NC}}$ interaction between the sulphur (S14) lone pair and the $\mathrm{N} 1=\mathrm{C} 2$ antibonding orbital gives stabilization by $23.77 \mathrm{kcal}_{\mathrm{mol}}{ }^{-1}$. The atoms $\mathrm{C} 2$, $\mathrm{C} 8$ and $\mathrm{C} 9$ are most prone to nucleophilic attack while the electrophilic attack on $\mathrm{C} 2, \mathrm{C} 4$ and $\mathrm{C} 8$ atoms. The $\mathrm{C} 2, \mathrm{C} 4, \mathrm{C} 8$ and $\mathrm{C} 9$ are more susceptible to free radical attack. The high first-order polarizability tensor reveals inductive interactions and second order polarizability tensors characterize the electron acceptor properties.
\end{abstract}

Keywords: 2-Mercaptobenzothiazole, DFT, Natural bond orbital, Hyperpolarizability, Reactivity descriptors.

\section{INTRODUCTION}

Accelarator, in the rubber industry, that causes vulcanization of rubber to occur more rapidly or at lower temperatures. Accelerators are basically amine derivatives and there are different classes of accelerators, aldehyde amines guanidines, thiazoles, sulfenamides, dithiocarbamates, thiuram sulfides, xanthates, thiocarbamyl sulfonamides. The most important accelarators being organic materials containing sulphur and nitrogen, especially derivatives of benzothiazole. 2-Mercaptobenzothiazole (MBT) is used primarily as a vulcanization accelerator in the production of natural and synthetic rubbers. 2-Mercaptobenzothiazole is also used in water treatment, lubricants and petroleum products as a corrosion inhibitor by inhibiting the formation of organic layers on metal surfaces. Other applications of 2-mercaptobenzothiazole include using it as a free radical polymerization initiator, as a chain transfer agent, as a reforming agent and as an assisting agent of photo- polymerization initiators for resins. 2-Mercaptobenzothiazole is also used as a reactant for various pharmaceuticals and pesticides.

During vulcanization the accelerators apparently converts the sulfur into a compound that reacts rapidly with rubber than does sulphur itself. An alternative possibility is that the accelerator reacts first with the rubber, changing it into a form that combines rapidly with sulfur. The first step in sulfur vulcanization is the formation of an active sulfurating species, which is a prerequisite for the formation of a crosslink precursor. A sulfurating species is a molecule that is able to insert sulfur in the form of crosslinks into the elastomer, where it has been long recognized that accelerator polysulfide complexes are better sulfurating species than molecular sulfur. These accelerator polysulfides are formed by the interaction of the accelerator molecule with molecular sulfur [1-3]. So, during that cross-linking formation, the mobility or the flexibility of the segments in between two cross-links are gradually changed

This is an open access journal, and articles are distributed under the terms of the Creative Commons Attribution-NonCommercial 4.0 International (CC BY-NC 4.0) License, which allows others to copy and redistribute the material in any medium or format, remix, transform, and build upon the material, as long as appropriate credit is given and the new creations are licensed under the identical terms. 
with the introduction of more and more sulfur cross-link bonds.

Studies have been carried out on the mechanism of 2mercaptobenzothiazole accelerated sulfur vulcanization of rubber with carbon black as filler. Results indicate that sulfuration by 2-mercaptobenzothiazole and sulfur proceed by a free radical mechanism but it becomes polar when $\mathrm{ZnO}$ and stearic acid are also present [4]. In this paper the role of thiol intermediates in 2-mercaptobenzothiazole accelerated sulfur vulcanization of rubber have been investigated. Density functional theory (DFT) has been becoming a useful tool used to investigate the charge density distribution, topological properties, electrostatic potential, frontier molecular orbitals, etc. The present investigation would be able to give some insight to the understanding of the charge transfer property of 2-mercaptobenzothiazole and to the influence of the functionalized moiety on the vulcanizing properties.

\section{COMPUTATIONAL METHODS}

The quantum chemical calculations have been performed with Gaussian-09 [5] program, invoking gradient geometry optimization [6]. The density functional theory (DFT) [7] with three parameter hybrid functional (B3) $[8,9]$ for the exchange part and the Lee-Yang-Parr (LYP) correlation functional [10] have been used for the computation of molecular structure and reactivity parameters using the standard $6-31 \mathrm{G}^{* *}, 6-$ $311++\mathrm{G}^{* *}$ and $\mathrm{cc}-\mathrm{pVDZ}$ basis sets.

Isoelectronic molecular electrostatic potential (MEP) and electron density [11] are calculated by using B3LYP/6$311++\mathrm{G}^{* *}$ method. The MEP explains hydrogen bonding, reactivity and structure-activity relationship of molecules including biomolecules and drugs [12]. The electron density surface mapped with electrostatic potential depicts the shape, size, charge density distribution and the sites of chemical reactivity of a molecule. GaussView 5.0.8 visualization program [13] has been utilized to construct the MEP surface and the shape of frontier molecular orbitals.

The stabilization energy $\mathrm{E}^{(2)}$ associated with $\mathrm{i}$ (donor) $\rightarrow$ $\mathrm{j}$ (acceptor) delocalization is estimated from the second-order perturbation approach [14-17]. Various reactivity and selectivity descriptors such as chemical hardness, chemical potential, softness, electrophilicity, nucleophilicity and the appropriate local reactivity descriptors are determined by employing the different kind of atomic charges (Mullikan charges, natural charges, electrostatic potential derived charges, Hirshfeld charges, Chelpg charges) of the neutral, cationic and anionic species of 2-mercaptobenzothiazole molecule.

The site-selectivity of a chemical system, can be determined by using Fukui functions $[18,19]$. The vertical ionization potential (I), electron affinity (A) and the electron populations are determined on the basis of B3LYP/6-311++G** method. The energy calculations of the $\mathrm{N}$-electron species are done using restricted B3LYP method while the energies of the $\mathrm{N}-1$ and $\mathrm{N}+1$ electronic species are calculated using open shell restricted B3LYP method by using B3LYP/6-311++G** optimized geometry of the N-electron species. The local reactivity descriptors of the individual atoms of the molecule $\mathrm{s}_{\mathrm{k}}^{\mathrm{a}}=\mathrm{f}_{\mathrm{k}}^{\mathrm{a}} \mathrm{S}$, $\omega_{\mathrm{k}}^{\mathrm{a}}=\omega \mathrm{f}_{\mathrm{k}}^{\mathrm{a}}$ and $\mathrm{f}_{\mathrm{k}}^{\mathrm{a}}$, where, $\mathrm{a}=+,-$ and 0 represents local philicity quantities describing nucleophilic, electrophilic and free radical attack, respectively.

The static dipole moment $(\mu)$, the mean polarizability $\left(\alpha_{0}\right)$, the anisotropy of the polarizability $(\Delta \alpha)$ and the mean hyperpolarizability $\left(\beta_{0}\right)$ using $\mathrm{x}, \mathrm{y}$ and $\mathrm{z}$ components are determined.

\section{RESULTS AND DISCUSSION}

Structural properties: The optimized geometry and the total electron density mapped electrostatic potential surface of the 2-mercaptobenzothiazole is shown in Fig. 1(a-b). The molecule belongs to $C_{s}$ point group. The optimized structural parameters namely bond length, bond angle and the dihedral angle for the stable geometry of 2-mercaptobenzothiazole molecule determined by B3LYP methods are given in Table1. No significant differences are observed in the $\mathrm{C}-\mathrm{C}$ bond lengths of aromatic benzene ring. The bond length $\mathrm{C} 2-\mathrm{S} 3$ is $0.01 \AA$ longer than the $\mathrm{C} 2-\mathrm{S} 14$ bond distances of the thiazole moiety. Easy delocalization of the lone pair electrons of S3 towards $\mathrm{N} 1=\mathrm{C} 2$ is possible and thereby decreases in force constant and increase in C2-S3 bond length than C2-S14. Similarly, the C8-C9 bond distance increases due to the electron withdrawing nature of nitrogen by the partial ionic nature. The shorter $\mathrm{S} 3-\mathrm{C} 9$ bond $(1.76 \AA)$ is in favour of the delocalization of sulphur (S3) lone pair of electrons towards the aromatic ring.

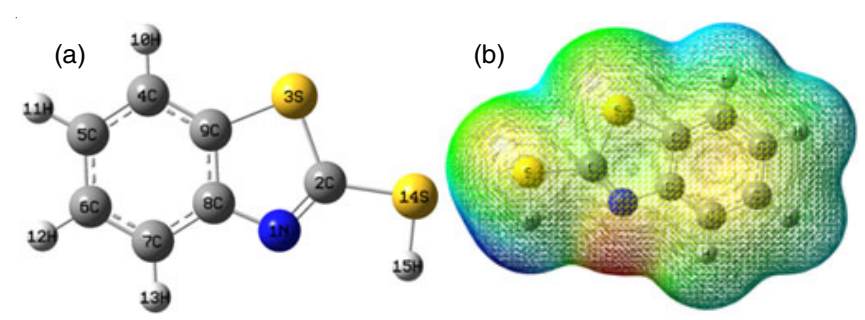

Fig. 1. (a) Optimized geometry and (b) Total electron density mapped electrostatic potential surface of 2-mercaptobenzothiazole

Analyzing the bond angle of aromatic ring of 2-mercaptobenzothiazole, the geometry of the benzene ring is relatively perturbed due to the presence of nitrogen and sulphur attachments. The bond angles C4-C5-C6 $\left(120.9^{\circ}\right), \mathrm{C} 5-\mathrm{C} 6-\mathrm{C} 7$ $\left(121^{\circ}\right)$ and $\mathrm{C} 4-\mathrm{C} 9-\mathrm{C} 8\left(121.7^{\circ}\right)$ are greater than $120^{\circ}$ whereas the bond angles $\mathrm{C} 5-\mathrm{C} 4-\mathrm{C} 9\left(118^{\circ}\right), \mathrm{C} 6-\mathrm{C} 7-\mathrm{C} 8\left(119^{\circ}\right)$ and C7-C8-C9 $\left(119.5^{\circ}\right)$ are less than $120^{\circ}$ indicates the electron withdrawing/donating influence of nitrogen and sulphur atoms. The present theoretical structural parameters of 2-mercaptobenzothiazole are well correlated with the XRD values of 1,2bis(benzothiazol-2-ylthio)ethane [bis(BT-NS)Et] [20]. The slight distortions from the X-ray geometry of bis(BT-NS)Et may arise from the packing effects in the solid state. The $\mathrm{C}-\mathrm{H}$ bond length of aromatic ring is also well agreed with the neutron diffraction measurements that are known to obtain more accurate C-H bond lengths that is $1.09 \AA$ [21] (Table-1), similar to the present computational results.

Analysis of molecular electrostatic potential: The total electron density mapped electrostatic potential surface of 2mercaptobenzothiazole is presented in Fig. 1(b). Local negative electrostatic potentials (red) reside on nitrogen which corresponds to the most nucleophilic regions, whereas local positive 


\begin{tabular}{|c|c|c|c|c|}
\hline \multicolumn{5}{|c|}{$\begin{array}{c}\text { TABLE-1 } \\
\text { STRUCTURAL PARAMETERS OF } \\
\text { 2-MERCAPTOBENZOTHIAZOLE DETERMINED BY B3LYP } \\
\text { METHOD WITH 6-31G**, 6-311++G** and cc-pVDZ BASIS SETS }\end{array}$} \\
\hline $\begin{array}{c}\text { Structural } \\
\text { parameters }\end{array}$ & $\begin{array}{c}\text { B3LYP/6- } \\
31 \mathrm{G}^{* *}\end{array}$ & $\begin{array}{l}\text { B3LYP/6- } \\
311++G^{* *}\end{array}$ & $\begin{array}{c}\text { B3LYP/cc- } \\
\text { pVDZ }\end{array}$ & Expt. $^{a}$ \\
\hline \multicolumn{5}{|c|}{ Internuclear distance $(\AA)$} \\
\hline $\mathrm{N} 1-\mathrm{C} 2$ & 1.29 & 1.29 & 1.29 & 1.293 \\
\hline $\mathrm{N} 1-\mathrm{C} 8$ & 1.39 & 1.39 & 1.39 & 1.399 \\
\hline $\mathrm{C} 2-\mathrm{S} 3$ & 1.78 & 1.78 & 1.78 & 1.751 \\
\hline $\mathrm{C} 2-\mathrm{S} 14$ & 1.77 & 1.77 & 1.77 & 1.744 \\
\hline S3-C9 & 1.76 & 1.76 & 1.76 & 1.729 \\
\hline $\mathrm{C} 4-\mathrm{C} 5$ & 1.39 & 1.39 & 1.40 & 1.374 \\
\hline C4-C9 & 1.40 & 1.39 & 1.40 & 1.389 \\
\hline C5-C6 & 1.40 & 1.40 & 1.41 & 1.389 \\
\hline $\mathrm{C} 6-\mathrm{C} 7$ & 1.39 & 1.39 & 1.39 & 1.378 \\
\hline $\mathrm{C} 7-\mathrm{C} 8$ & 1.40 & 1.40 & 1.40 & 1.384 \\
\hline $\mathrm{C} 8-\mathrm{C} 9$ & 1.42 & 1.41 & 1.42 & 1.406 \\
\hline $\mathrm{C}-\mathrm{H}(\text { ring })^{\mathrm{b}}$ & 1.09 & 1.08 & 1.09 & 1.09 \\
\hline S14-H15 & 1.35 & 1.35 & 1.36 & - \\
\hline \multicolumn{5}{|c|}{ Bond angle $\left({ }^{\circ}\right)$} \\
\hline $\mathrm{C} 2-\mathrm{N} 1-\mathrm{C} 8$ & 110.7 & 111.0 & 110.7 & 110.1 \\
\hline $\mathrm{N} 1-\mathrm{C} 2-\mathrm{S} 3$ & 116.6 & 116.4 & 116.6 & 116.6 \\
\hline N1-C2-S14 & 124.7 & 125.0 & 124.8 & 127.3 \\
\hline S3-C2-S14 & 118.6 & 118.6 & 118.6 & 116.1 \\
\hline C2-S3-C9 & 87.9 & 88.0 & 87.8 & 88.8 \\
\hline C5-C4-C9 & 118.0 & 118.0 & 118.0 & 118.3 \\
\hline C5-C4-H10 & 120.8 & 120.8 & 120.8 & - \\
\hline C9-C4-H10 & 121.2 & 121.3 & 121.2 & - \\
\hline C4-C5-C6 & 121.0 & 120.9 & 120.9 & 121.2 \\
\hline C4-C5-H11 & 119.3 & 119.4 & 119.3 & - \\
\hline C6-C5-H11 & 119.7 & 119.7 & 119.7 & - \\
\hline C5-C6-C7 & 120.9 & 121.0 & 120.9 & 120.6 \\
\hline C5-C6-H12 & 119.5 & 119.4 & 119.5 & - \\
\hline C7-C6-H12 & 119.6 & 119.6 & 119.6 & - \\
\hline C6-C7-C8 & 119.0 & 119.0 & 119.1 & 119.3 \\
\hline C6-C7-H13 & 121.8 & 121.7 & 121.8 & - \\
\hline C8-C7-H13 & 119.3 & 119.4 & 119.2 & - \\
\hline $\mathrm{N} 1-\mathrm{C} 8-\mathrm{C} 7$ & 124.9 & 125.2 & 125.0 & 125.4 \\
\hline N1-C8-C9 & 115.5 & 115.4 & 115.6 & 114.9 \\
\hline C7-C8-C9 & 119.5 & 119.5 & 119.4 & 119.7 \\
\hline S3-C9-C4 & 129.2 & 129.1 & 129.1 & 129.5 \\
\hline S3-C9-C8 & 109.3 & 109.3 & 109.2 & 109.6 \\
\hline C4-C9-C8 & 121.6 & 121.7 & 121.7 & - \\
\hline C2-S14-H15 & 93.6 & 93.5 & 93.2 & - \\
\hline
\end{tabular}

${ }^{a}$ Values are taken from [Ref. 20]; ${ }^{b}$ Values are taken from [Ref. 21].

electrostatic potentials (blue) lie on hydrogen in S-H group which represents the most electrophilic regions. Green areas cover parts of the molecule where electrostatic potentials are close to zero ( $\mathrm{C}-\mathrm{C}$ bonds). The MEP of the molecule lie in the range $+1.238 \mathrm{e} \times 10^{-2}$ to $-1.238 \mathrm{e} \times 10^{-2}$. The total electron density of 2-mercaptobenzothiazole lie in the range $+3.143 \mathrm{e} \times 10^{-2}$ to $-3.143 \mathrm{e} \times 10^{-2}$. The MEP and total electron density shows that the 2-mercaptobenzothiazole is more polar and reactive. Electrostatic potential is used to find the electrophilic or nucleophilic sites that play a crucial role in molecular recognition. It is noteworthy that the electrostatic forces have a long-distance character and they determine the path along which the reactant molecules approach each other.

Analysis of frontier molecular orbitals: The energies of HOMO, LUMO, LUMO+1 and HOMO-1 and the LUMOHOMO energy gap are calculated by using B3LYP/6-311++G** method. The calculated LUMO-HOMO energy gap explains the ultimate charge transfer interface within the molecule. The hardness and softness of the molecule depends on the frontier molecular orbital energies. The LUMO-HOMO energy gaps of 2-mercaptobenzothiazole determined by B3LYP/6$311++\mathrm{G}^{* *}$ method is $5.1370 \mathrm{eV}$. The molecular orbital energies and global reactivity properties of 2-mercaptobenzothiazole determined by B3LYP/6-311++G** method are summarized in Table-2.

According to the frontier molecular orbital theory (FMO) of chemical reactivity, the formation of a transition state is due to an interaction between the frontier orbitals (HOMO and LUMO) of reacting species [22,23]. The energy of the $\mathrm{HOMO}$ is directly related to the ionization potential and chracterises the susceptibility of the molecule towards attack by electrophiles. The HOMO-LUMO gap, i.e. the difference in energy between the HOMO and LUMO, is an important stability index [24]. A large HOMO-LUMO gap implies high stability for the molecule in the sense of its lower reactivity in chemical reactions [25]. The qualitative definition of hardness is closely related to the polarizability, since a decrease of the energy gap usually leads to easier polarization of the molecule [26].

Natural bond orbital (NBO) analysis: The hyperconjugative interaction energy was deduced from the second-order perturbation approach of Fock Matrix in NBO basis between donor-acceptor orbitals [27]. The NBO method demonstrates the bonding concepts like atomic charge, Lewis structure, bond type, hybridization, bond order, charge transfer and resonance possibilities. The bonding concepts such as type of bond orbital, their occupancies, the natural atomic hybrids of which the NBO is composed, giving the percentage of the NBO on each hybrid, the atom label and a hybrid label showing the hybrid orbital $\left(s p^{x}\right)$ composition (the amount of $s$-character, $p$-character, etc.) of 2-mercaptobenzothiazole determined by B3LYP/6$311++\mathrm{G}^{* *}$ method. All bonding donor orbitals have two electrons. The bonding orbital for $\mathrm{C} 4-\mathrm{C} 5$ has $50.78 \% \mathrm{C} 4$ character in a $s p^{1.76}$ hybrid and has $49.22 \%$ C5 character in a $s p^{1.80}$ hybrid orbital. The bonding orbital for C5-C6 has 50.06 $\%$ C5 character in a $s p^{1.79}$ hybrid and has $49.94 \%$ C6 character in a $s p^{1.81}$ hybrid orbital. The bonding orbital for N1-C2 with

TABLE-2

CALCULATED MOLECULAR ORBITAL ENERGIES AND GLOBAL REACTIVITY PROPERTIES OF 2-MERCAPTO BENZOTHIAZOLE BY B3LYP/6-311++G** METHOD

\begin{tabular}{cccccc}
\hline $\mathrm{E}_{\mathrm{LUMO}+1}(\mathrm{eV})$ & $\mathrm{E}_{\mathrm{LUMO}}(\mathrm{eV})$ & $\mathrm{E}_{\mathrm{HOMO}}(\mathrm{eV})$ & $\mathrm{E}_{\mathrm{HOMO}-1}(\mathrm{eV})$ & $\mathrm{E}_{\mathrm{LUMO}}-\mathrm{E}_{\mathrm{HOMO}}(\mathrm{eV})$ & $\begin{array}{c}\text { Ionization } \\
\text { potential, } \mathrm{I}(\mathrm{eV})\end{array}$ \\
\hline-0.7617 & -1.3372 & -6.4742 & -6.8086 & 5.1370 & 8.2737 \\
\hline $\begin{array}{c}\text { Electron } \\
\text { affinity, } \mathrm{A}(\mathrm{eV})\end{array}$ & Electronegativity $(\chi)$ & $\begin{array}{c}\text { Chemical } \\
\text { potential }(\mu)\end{array}$ & Electrophilicity $(\omega)$ & Hardness $(\eta)$ & Softness $(\mathrm{S})$ \\
\hline-0.3417 & 3.9660 & -3.9660 & 1.8257 & 4.3077 & 0.1161 \\
\hline
\end{tabular}


1.9894 electrons has $59.61 \% \mathrm{~N} 1$ character and $40.39 \% \mathrm{C} 1$ character in a $s p^{1.62}$ hybrid orbital. The bonding orbital for $\mathrm{C} 2-$ $\mathrm{S} 3$ has $52.70 \% \mathrm{C} 2$ character and $47.30 \% \mathrm{~S} 3$ character. The $\mathrm{C}-\mathrm{C}$ bonds of the benzene ring possess more $p$ character than $s$ character. This clearly indicates the delocalization of $\pi$ electrons among all the carbon atoms.

The Fock matrix analysis yield different types of donoracceptor interactions and their stabilization energy. This bonding-antibonding interactions can be quantitatively described in terms of the NBO approach that is expressed by means of second-order perturbation interaction energy $\mathrm{E}^{(2)}$ [14-17]. This energy represents the estimation of the off-diagonal NBO Fock matrix element. Second order perturbation theory analysis of Fock matrix of 2-mercaptobenzothiazole using NBO analysis are presented in Table- 3 . The lone pair donor orbital, $\mathrm{n}_{\mathrm{S}} \pi^{*}{ }_{\mathrm{NC}}$ interaction between the sulphur (S3) lone pair and the N1=C2 antibonding orbital gives strong stabilization by $26.70 \mathrm{kcal}$ $\mathrm{mol}^{-1}$. The lone pair donor orbital, $\mathrm{n}_{\mathrm{S}} \pi^{*}{ }_{\mathrm{NC}}$ interaction between the sulphur (S14) lone pair and the $\mathrm{N} 1=\mathrm{C} 2$ antibonding orbital gives strong stabilization by $23.77 \mathrm{kcal} \mathrm{mol}^{-1}$. The bond pair donor orbital, $\pi_{\mathrm{CC}} \pi^{*} \mathrm{CC}$ interaction between the $\mathrm{C} 6-\mathrm{C} 7$ bond pair and the antiperiplanar $\mathrm{C} 8=\mathrm{C} 9$ antibonding orbital give stabilization of $21.25 \mathrm{kcal} \mathrm{mol}^{-1}$.

TABLE-3

SECOND ORDER PERTURBATION THEORY ANALYSIS OF FOCK MATRIX OF 2-MERCAPTO BENZOTHIAZOLE BY B3LYP/6-311++G** METHOD USING NBO ANALYSIS

\begin{tabular}{lccc}
\hline $\begin{array}{c}\text { Donor (i) }- \text { Acceptor }(\mathrm{j}) \\
\text { interaction }\end{array}$ & $\begin{array}{c}\mathrm{E}^{(2) \mathrm{a}} \\
\left(\mathrm{kcal} \mathrm{mol}^{-1}\right)\end{array}$ & $\begin{array}{c}\mathrm{E}(\mathrm{j})-\mathrm{E}(\mathrm{i})^{\mathrm{b}} \\
(\text { a.u. })\end{array}$ & $\begin{array}{c}\mathrm{F}(\mathrm{i}, \mathrm{j})^{\mathrm{e}} \\
(\text { a.u. })\end{array}$ \\
\hline$\pi(\mathrm{N} 1-\mathrm{C} 2) \rightarrow \pi^{*}(\mathrm{C} 8-\mathrm{C} 9)$ & 14.62 & 0.35 & 0.071 \\
$\pi(\mathrm{C} 4=\mathrm{C} 5) \rightarrow \pi^{*}(\mathrm{C} 6=\mathrm{C} 7)$ & 18.90 & 0.29 & 0.066 \\
$\pi(\mathrm{C} 4=\mathrm{C} 5) \rightarrow \pi^{*}(\mathrm{C} 8=\mathrm{C} 9)$ & 18.78 & 0.27 & 0.066 \\
$\pi(\mathrm{C} 6=\mathrm{C} 7) \rightarrow \pi^{*}(\mathrm{C} 4=\mathrm{C} 5)$ & 19.82 & 0.28 & 0.067 \\
$\pi(\mathrm{C} 6=\mathrm{C} 7) \rightarrow \pi^{*}(\mathrm{C} 8=\mathrm{C} 9)$ & 21.25 & 0.26 & 0.07 \\
$\pi(\mathrm{C} 8=\mathrm{C} 9) \rightarrow \pi^{*}(\mathrm{~N} 1=\mathrm{C} 2)$ & 12.44 & 0.25 & 0.050 \\
$\pi(\mathrm{C} 8=\mathrm{C} 9) \rightarrow \pi^{*}(\mathrm{C} 4=\mathrm{C} 5)$ & 19.47 & 0.3 & 0.068 \\
$\pi(\mathrm{C} 8=\mathrm{C} 9) \rightarrow \pi^{*}(\mathrm{C} 6=\mathrm{C} 7)$ & 16.19 & 0.3 & 0.063 \\
$\mathrm{n}(\mathrm{N} 1) \rightarrow \sigma^{*}(\mathrm{C} 2-\mathrm{S} 3)$ & 17.38 & 0.52 & 0.086 \\
$\mathrm{n}(\mathrm{S} 3) \rightarrow \pi^{*}(\mathrm{~N} 1=\mathrm{C} 2)$ & 26.70 & 0.24 & 0.072 \\
$\mathrm{n}(\mathrm{S} 3) \rightarrow \pi^{*}(\mathrm{C} 8=\mathrm{C} 9)$ & 17.61 & 0.27 & 0.064 \\
$\mathrm{n}(\mathrm{S} 14) \rightarrow \pi^{*}(\mathrm{~N} 1=\mathrm{C} 2)$ & 23.77 & 0.25 & 0.073 \\
\hline
\end{tabular}

\section{Analysis of structure-reactivity descriptors}

Topological charge distribution analysis: The different kind of atomic charges (Mullikan charges, natural charges, electrostatic potential derived charges, Hirschfield charges, Chelpg charges) of 2-mercaptobenzothiazole are calculated by using B3LYP/6-311++G** method and presented in Table-4. The chemical information obtained from charge density analysis enables us to know how the structure can exist, how the compound exhibits chemical and biological reactivity and where the interaction sites/regions localize. All the charges except Mulliken shows the nitrogen (N1) atom of thiazole moiety in neutral, cationic and anionic species possess negative charge due to its more electronegativity. In the neutral molecule, the sulphur (S3) has positive charge and very small negative charge by Chelpg method. This reveals the possibility of the nucleophilic attack at $\mathrm{S} 3$ on sulphurization process. Instead the sulphur atom S14 possesses negative charge except NBO method and these suggest that electrophilic attack predominate at this sulphur atom. In the cationic and anionic species of 2-mercaptobenzothiazole both the sulphur atoms possess positive and negative charges, respectively.

The $\mathrm{C} 2$ and $\mathrm{C} 8$ have positive charges due to the electronic effect of N1 atom. All these charge distribution in 2-mercaptobenzothiazole provides better understanding of chemical reactivity and clearly favours the sulphurization process and 2-mercaptobenzothiazole is considered the best vulcanization accelerator. The charge density of 2-mercaptobenzothiazole provides important and meaningful chemical information for better understanding the inherent properties of the compound. The calculated $\sigma-$ and $\pi$-electron densities on a particular atom also characterize the possible orientation of the chemical interactions and, thus, are often considered to be directional reactivity indices. In contrast, overall electron densities and net charges on atoms are considered as non-directional reactivity indices [17]. Atomic charges are also used for the description of the molecular polarity of molecules.

Dipole moment and polarity indices: The polarity of a molecule is well known to be important for various physicochemical properties and many descriptors have been proposed to quantify the polarity effects. The most obvious and most often used quantity to describe the polarity is the dipole moment

TABLE-4

ATOMIC CHARGES OF 2-MERCAPTOBENZOTHIAZOLE DETERMINED BY B3LYP/6-311++G** METHOD

\begin{tabular}{cccccc}
\hline Atom & Mulliken & NBO & ESP & Hirshfeld & Chelpg \\
\hline N1 & 0.1613 & -0.5073 & -0.5928 & -0.1614 & 0.0533 \\
C2 & 0.5549 & -0.0753 & 0.1652 & 0.0195 & -0.5964 \\
S3 & -0.5200 & 0.3769 & 0.0372 & -0.0397 & -0.0344 \\
C4 & 0.1157 & -0.2139 & -0.1081 & -0.0423 & -0.0802 \\
C5 & -0.1140 & -0.1988 & -0.2780 & -0.0428 & -0.0094 \\
C6 & -0.2939 & -0.2033 & -0.0383 & -0.0407 & -0.2987 \\
C7 & -0.8454 & -0.1870 & -0.4239 & 0.0362 & 0.5079 \\
C8 & -1.7812 & 0.1162 & 0.6679 & -0.0198 & -0.0922 \\
C9 & 2.1734 & -0.2003 & -0.1707 & 0.0525 & 0.0453 \\
H10 & 0.1748 & 0.2143 & 0.1781 & 0.0453 & 0.1327 \\
H11 & 0.1650 & 0.2079 & 0.1677 & 0.0501 & 0.0828 \\
H12 & 0.1699 & 0.2079 & 0.1365 & -0.0357 & 0.1429 \\
H13 & 0.1875 & 0.2199 & 0.1947 & -0.1957 \\
S14 & -0.2412 & 0.0902 & -0.1675 & 0.2320 & 0.2057 \\
H15 & 0.0930 & 0.1526 & &
\end{tabular}


of the molecule $[28,29]$. The total dipole moment, reflects only the global polarity of a molecule. The total dipole moment of 2-mercaptobenzothiazole is determined by B3LYP/6$311++\mathrm{G}^{* *}$ method is $1.0102 \mathrm{D}$ shows that the polar nature of 2-mercaptobenzothiazole molecule.

Fukui reactivity descriptors: Fukui functions and local softness are extensively applied to probe the local reactivity and site selectivity. The formal definitions of all these descriptors and working equations for their computation have been described [30,31]. The Fukui functions $\left(f_{k}\right)$ of the individual atoms of the neutral, cationic and anionic species of 2-mercaptobenzothiazole calculated by B3LYP/6-311++G** method. In the present study, both the local reactivity and multiphilicity descriptors are used to probe the nature of attack/reactivity at a particular site in the molecule. The Fukui dual reactivity descriptor $\left(\Delta \mathrm{f}_{\mathrm{k}}\right)$, the dual local softness $\left(\Delta \mathrm{s}_{\mathrm{k}}\right)$ and the multiphilicity descriptors $\left(\Delta \omega_{\mathrm{k}}\right)$ which can concurrently characterize both nucleophilic and electrophilic nature of a chemical species.
The Fukui dual reactivity descriptors $\left(\Delta \mathrm{f}_{\mathrm{k}}\right)($ Table-5), the dual local softness $\left(\Delta \mathrm{s}_{\mathrm{k}}\right)$ (Table-6) and the multiphilicity descriptors $\left(\Delta \omega_{k}\right)$ (Table-7) have also been determined to predict the reactive sites of the 2-mercaptobenzothiazole molecule. The relative thermodynamic and kinetic stabilities are discussed through the hardness and softness of the molecule. The hardness of 2-mercaptobenzothiazole determined by B3LYP/ $6-311++\mathrm{G}^{* *}$ method is $4.3077 \mathrm{eV}$ while the softness is $0.1161 \mathrm{eV}$.

In the present investigation the atoms $\mathrm{C} 2, \mathrm{C} 8$ and $\mathrm{C} 9$ are most prone to nucleophilic attack while the electrophilic attack is more on $\mathrm{C} 2, \mathrm{C} 4$ and $\mathrm{C} 8$ atoms. The sites $\mathrm{C} 2, \mathrm{C} 4, \mathrm{C} 8$ and $\mathrm{C} 9$ are more susceptible to free radical attack.

If $\Delta \mathrm{f}_{\mathrm{k}}, \Delta \mathrm{s}_{\mathrm{k}}$ and $\Delta \omega_{\mathrm{k}}$ are greater than zero, then the site $\mathrm{k}$ is favoured for a nucleophilic attack, whereas if these are less than zero, then the site $\mathrm{k}$ may be favoured for an electrophilic attack. From Fukui dual reactivity descriptor $\left(\Delta \mathrm{f}_{\mathrm{k}}\right)$, the dual local softness $\left(\Delta \mathrm{s}_{\mathrm{k}}\right)$ and the multiphilicity descriptors $\left(\Delta \omega_{\mathrm{k}}\right)$ one can understand that the atoms C8, C9 and S14 are more favourable for nucleophilic attack. The atoms N1, S3, C2 and

TABLE-5

FUKUI DUAL DESCRIPTORS $\left(\Delta \mathrm{f}_{\mathrm{k}}\right)$ OF 2-MERCAPTOBENZOTHIAZOLE BY B3LYP/6-311++G** METHOD

\begin{tabular}{cccccc}
\hline Atom & Mulliken & NBO & ESP & Hirshfeld & Chelpg \\
\hline N1 & -0.0068 & -0.0149 & -0.0754 & -0.0135 & -0.0794 \\
C2 & 0.0281 & -0.1435 & 0.0531 & -0.0586 & -0.0271 \\
S3 & -0.0798 & -0.0360 & -0.1138 & -0.0423 & -0.05212 \\
C4 & -0.0192 & -0.0510 & 0.0002 & -0.0136 & 0.0099 \\
C5 & -0.0306 & 0.0119 & -0.0044 & 0.0141 & 0.0752 \\
C6 & 0.0333 & 0.0360 & 0.0585 & -0.0167 & -0.0639 \\
C7 & -0.0381 & -0.0591 & -0.1135 & 0.0253 & 0.1057 \\
C8 & 0.0009 & 0.0502 & 0.1155 & 0.0289 & 0.0690 \\
C9 & 0.0663 & 0.0502 & 0.0379 & 0.0457 & 0.0649 \\
S14 & 0.0318 & 0.1444 & &
\end{tabular}

TABLE-6

DUAL LOCAL SOFTNESS DESCRIPTORS $\left(\Delta \mathrm{s}_{\mathrm{k}}\right)$ OF 2-MERCAPTOBENZOTHIAZOLE BY B3LYP/6-311++G** METHOD

\begin{tabular}{cccccc}
\hline Atom & Mulliken & NBO & ESP & Hirshfeld & Chelpg \\
N1 & -0.0008 & -0.0017 & -0.0088 & -0.0016 & -0.0092 \\
C2 & 0.0033 & -0.0167 & 0.0062 & -0.0068 & -0.0031 \\
S3 & -0.0093 & -0.0042 & -0.0132 & -0.0016 & -0.0061 \\
C4 & -0.0022 & -0.0059 & 0.0000 & 0.0012 & 0.0087 \\
C5 & -0.0036 & 0.0014 & -0.0005 & 0.0016 & 0.0024 \\
C6 & 0.0039 & 0.0042 & 0.0068 & -0.0019 & -0.0074 \\
C7 & -0.0044 & -0.0069 & -0.0132 & 0.0029 & 0.0123 \\
C8 & 0.0001 & 0.0058 & 0.0134 & 0.0034 & 0.0080 \\
C9 & 0.0077 & 0.0058 & 0.0044 & 0.0088 & 0.0075 \\
S14 & 0.0037 & 0.0168 & 0.0052 & & \\
\hline
\end{tabular}

TABLE-7

MULTIPHILICITY DESCRIPTORS $\left(\Delta \omega_{\mathrm{k}}\right)$ OF 2-MERCAPTOBENZOTHIAZOLE BY B3LYP/6-311++G** METHOD

\begin{tabular}{|c|c|c|c|c|c|}
\hline Atom & Mulliken & NBO & ESP & Hirshfeld & Chelpg \\
\hline N1 & -0.0125 & -0.0271 & -0.1377 & -0.0247 & -0.1450 \\
\hline $\mathrm{C} 2$ & 0.0513 & -0.2621 & 0.0969 & -0.1070 & 0.0494 \\
\hline S3 & -0.1456 & -0.0657 & -0.2078 & -0.0772 & -0.2030 \\
\hline $\mathrm{C} 4$ & -0.0351 & -0.0932 & 0.0004 & -0.0247 & -0.0952 \\
\hline C5 & -0.0559 & 0.0217 & -0.0080 & 0.0181 & 0.1372 \\
\hline C6 & 0.0608 & 0.0656 & 0.1067 & 0.0258 & 0.0373 \\
\hline $\mathrm{C} 7$ & -0.0696 & -0.1079 & -0.2072 & -0.0304 & -0.1166 \\
\hline $\mathrm{C} 8$ & 0.0016 & 0.0917 & 0.2108 & 0.0461 & 0.1930 \\
\hline C9 & 0.1210 & 0.0916 & 0.0691 & 0.0529 & 0.1259 \\
\hline S14 & 0.0580 & 0.2636 & 0.0816 & 0.1382 & 0.1184 \\
\hline
\end{tabular}


C7 are more favourable for electrophilic attack. The Fukui functions which represent the relative nucleophilic and electrophilic are shown in the Figs. 2(a) and (b). The free radical descriptors and the Fukui dual descriptor $\left(\Delta \mathrm{f}_{\mathrm{k}}\right)$, the dual local softness $\left(\Delta \mathrm{s}_{\mathrm{k}}\right)$ and the multiphilicity descriptors $\left(\Delta \omega_{\mathrm{k}}\right)$ of mercaptobenzothiazole are shown in Figs. 3(i) and (ii).
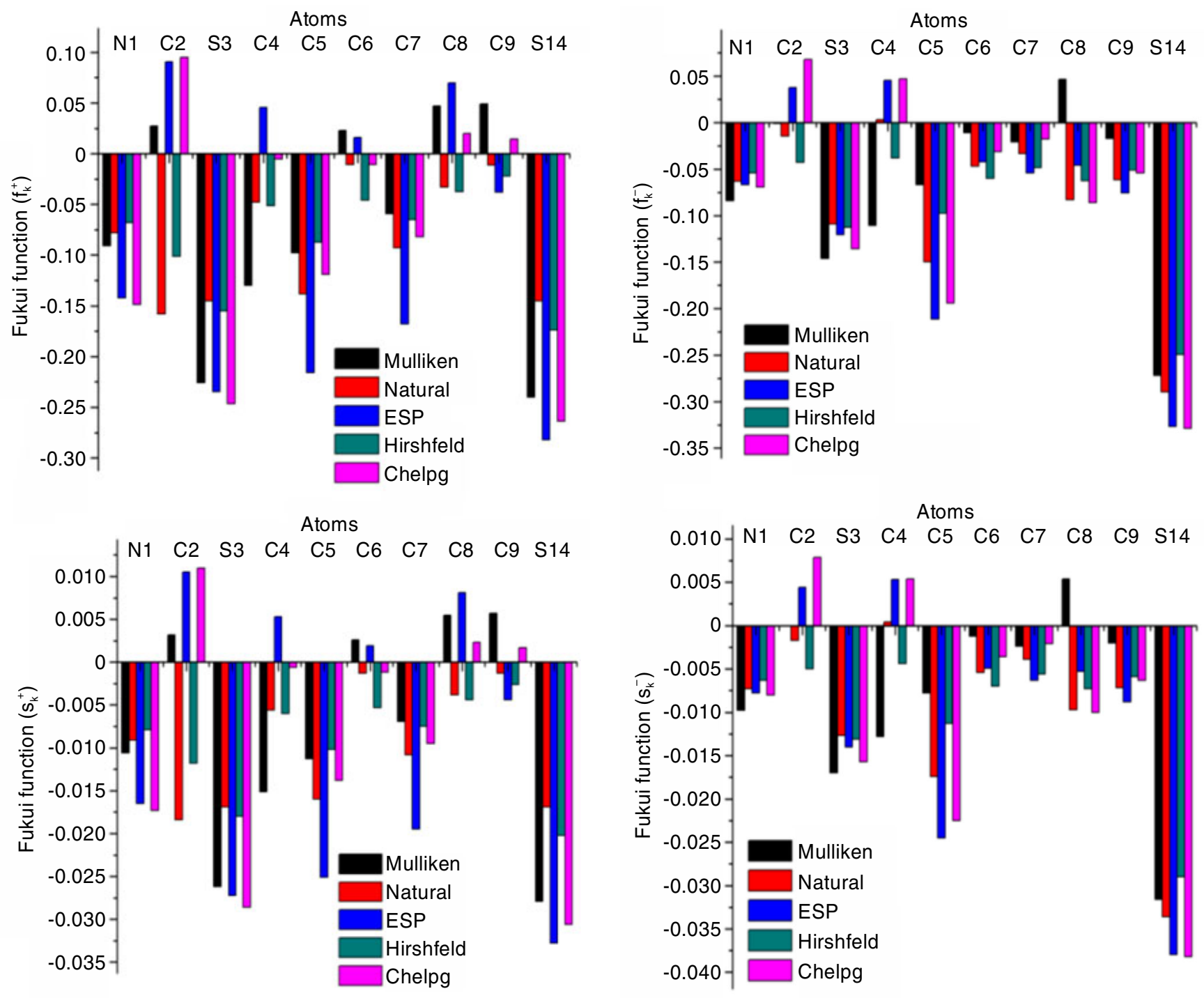

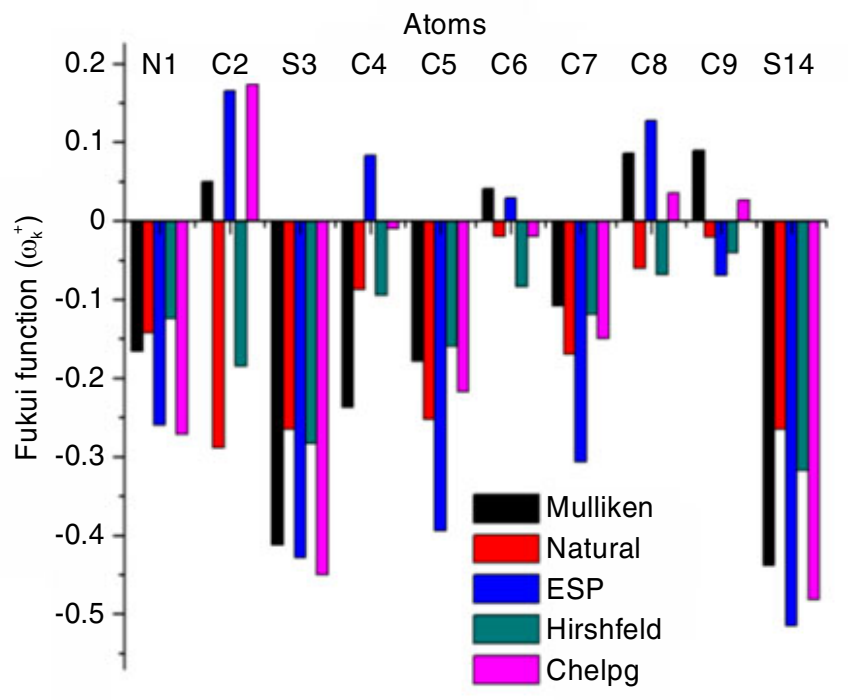

(a)

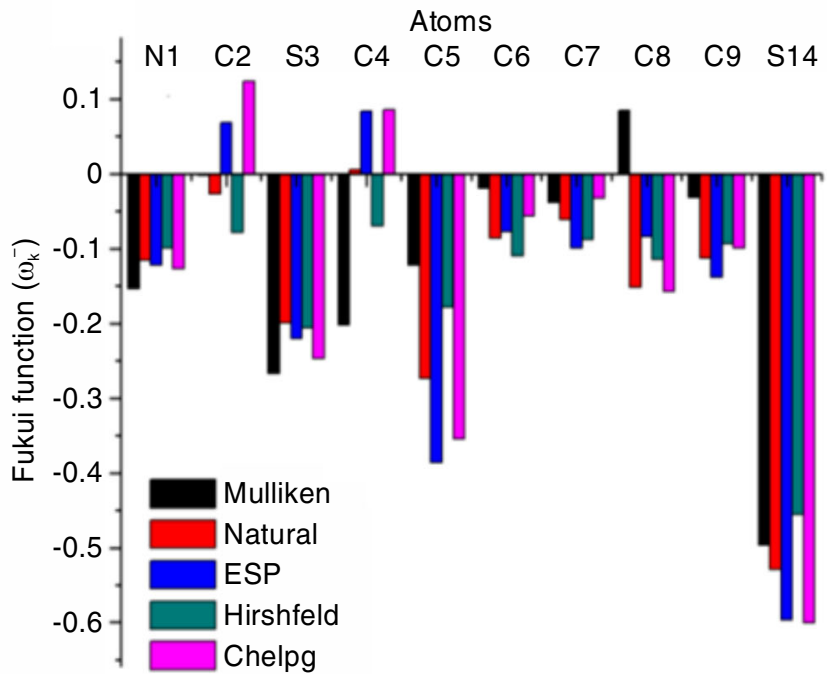

(b)

Fig. 2. (a) Relative nucleophilic and (b) relative electrophilic descriptors of mercapto benzothiazole 

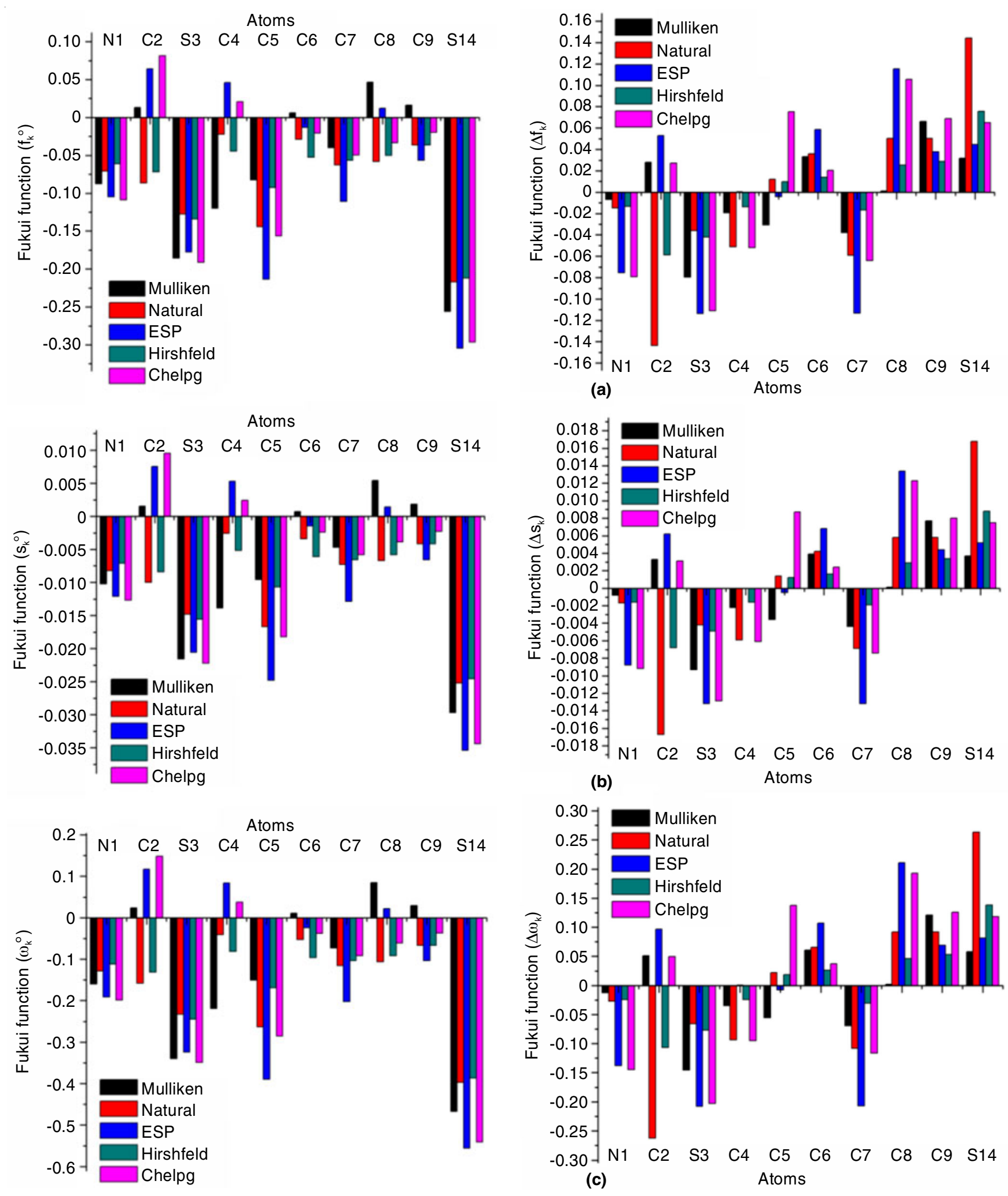

(i)

(ii)

Fig. 3. (i) Relative free radical descriptors and (ii) (a) dual descriptor $\left(\Delta \mathrm{f}_{\mathrm{k}}\right)$, (b) the dual local softness $\left(\Delta \mathrm{s}_{\mathrm{k}}\right)$ and (c) the multiphilicity descriptors $\left(\Delta \omega_{\mathrm{k}}\right)$ of mercaptobenzothiazole

Molecular polarizability and hyperpolarizability analysis: The polarizabilities are related to hydrophobicity and other biological activities [32]. The first hyperpolarizability of 2mercaptobenzothiazole computed by B3LYP/6-311++G** method are presented in the Table- 8 . The hyperpolarizability $(\beta)$ which is a measure of the non-linear optical activity of the molecular system, is associated with the intramolecular charge transfer, resulting from the electron cloud movement through 
TABLE-8

DIPOLE MOMENT, AVERAGE POLARIZABILITY, FIRST POLARIZABILITY AND HYPERPOLARIZABILITY TENSORS OF 2-MERCAPTOBENZOTHIAZOLE DETERMINED BY B3LYP/6-311++G(d,p) METHOD

\begin{tabular}{|c|c|c|c|c|c|}
\hline$\mu_{\text {total }}(\mathrm{D})$ & 1.0102 & $\alpha_{\text {total }}($ e.s.u) & $57.1418 \times 10^{-24}$ & $\beta_{\mathrm{yzz}}$ & 19.3551 \\
\hline$\alpha_{x x}$ & 193.9302 & $\Delta \alpha($ a.u $)$ & 108.0139 & $\beta_{\mathrm{zzz}}$ & 0.0313 \\
\hline$\alpha_{x y}$ & -0.9530 & $\beta_{x x x}$ & 486.9225 & $\beta_{\mathrm{x}}$ & 470.2948 \\
\hline$\alpha_{y y}$ & 123.0201 & $\beta_{\mathrm{xxy}}$ & 36.6944 & $\beta_{\mathrm{x}}^{2}$ & $22.1177 \times 10^{4}$ \\
\hline$\alpha_{x z}$ & 0.0030 & $\beta_{\mathrm{xyy}}$ & 2.8191 & $\beta_{\mathrm{y}}$ & 59.1596 \\
\hline$\alpha_{y z}$ & 0.0009 & $\beta_{\text {yyy }}$ & 3.1101 & $\beta_{\mathrm{y}}{ }^{2}$ & $34.9986 \times 10^{2}$ \\
\hline$\alpha_{z z}$ & 69.6334 & $\beta_{\mathrm{xxz}}$ & -0.3184 & $\beta_{z}$ & -0.2794 \\
\hline$\alpha_{0}($ a.u $)$ & 128.8612 & $\beta_{\mathrm{xyz}}$ & 0.0116 & $\beta_{\mathrm{z}}^{2}$ & $78.0644 \times 10^{-3}$ \\
\hline$\alpha_{0}($ e.s.u $)$ & $19.0941 \times 10^{-24}$ & $\beta_{\mathrm{yyz}}$ & 0.0077 & $\beta_{0}(\mathrm{a} . \mathrm{u})$ & $22.4677 \times 10^{4}$ \\
\hline$\alpha_{\text {total }}$ (a.u) & 385.6345 & $\beta_{\mathrm{xzz}}$ & -19.4468 & $\beta_{0}$ (e.s.u) & $19.4119 \times 10^{-28}$ \\
\hline
\end{tabular}

$\pi$ conjugated frame work from electron donor to electron acceptor groups. Molecules with high hyperpolarizability have chromophores, since the compound 2-mercaptobenzothiazole is a conjugative system with $\mathrm{S}-\mathrm{H}$ chromophore and hence its hyperpolarizability values determined are in the order of more than $10 \times 10^{-24}$ e.s.u. [33]. The asymmetric molecule 2-mercaptobenzothiazole has large values of molecular hyperpolarizability, $\beta$ due to the electron delocalization along a conjugated backbone.

Furthermore, the electronic polarizability of molecules shares common features with the electrophilic super delocalizability. The first-order polarizability tensor contains information about possible inductive interactions in the 2-mercaptobenzothiazole molecule. The total anisotropy of the polarizability (second-order term) characterize the electron acceptor properties of 2-mercaptobenzothiazole molecule.

\section{Conclusion}

The following observations are made from the present investigations:

- The structure of 2-mercaptobenzothiazole is optimized and the bond length, bond angle and dihedral angle are determined by using B3LYP method with 6-31G**, 6-311++G** and cc-pVDZ basis sets.

- The $\mathrm{C}=\mathrm{N}$ and $\mathrm{S}-\mathrm{H}$ are syn with respect to $\mathrm{C} 2-\mathrm{S} 14$ bond. The intramolecular hydrogen bonding of the type $\mathrm{S}-\mathrm{H} \cdots \mathrm{N}$ is the power of enforcing the existence of syn conformation.

- Local negative electrostatic potentials (red) reside on nitrogen which corresponds to the most nucleophilic regions, whereas local positive electrostatic potentials (blue) lie on hydrogen in S-H group which represents the most electrophilic regions.

- The MEP of the molecule lie in the range from $+1.238 \mathrm{e}$ $\times 10^{-2}$ to $-1.238 \mathrm{e} \times 10^{-2}$. The total electron density of 2 -mercaptobenzothiazole lie in the range from $+3.143 \mathrm{e} \times 10^{-2}$ to $-3.143 \mathrm{e}$ $\times 10^{-2}$.

- The LUMO-HOMO energy gap of 2-mercaptobenzothiazole is $5.1370 \mathrm{eV}$. The energy gap is not too high and the molecule is reactive enough.

- The bonding orbital for N1-C2 with 1.9894 electrons has $59.61 \% \mathrm{~N} 1$ character and $40.39 \% \mathrm{C} 1$ character in a $s p^{1.62}$ hybrid orbital. The bonding orbital for $\mathrm{C} 2-\mathrm{S} 3$ has $52.70 \% \mathrm{C} 2$ character and $47.30 \% \mathrm{~S} 3$ character.

- The lone pair donor orbital, $\mathrm{n}_{\mathrm{S}} \pi^{*}{ }_{\mathrm{NC}}$ interaction between $\mathrm{S} 3$ and $\mathrm{N} 1=\mathrm{C} 2$ antibonding orbital gives strong stabilization by $26.70 \mathrm{kcal} \mathrm{mol}^{-1}$, while between the sulphur (S14) lone pair and the $\mathrm{N} 1=\mathrm{C} 2$ antibonding orbital gives strong stabilization by $23.77 \mathrm{kcal} \mathrm{mol}^{-1}$.

- In the neutral molecule, the sulphur (S3) has positive charge and very small negative Chelpg charge. This reveals the possibility of the nucleophilic attack at S3 on sulphurization process. Instead another sulphur atom S14 possesses negative charge except NBO method and these suggest that electrophilic attack predominate at this sulphur atom.

- The local philicity quantities represents the atoms $\mathrm{C} 2$, $\mathrm{C} 8$ and $\mathrm{C} 9$ are most prone to nucleophilic attack while the electrophilic attack is more on $\mathrm{C} 2, \mathrm{C} 4$ and $\mathrm{C} 8$ atoms. The sites C2, C4, C8 and C9 are more susceptible to free radical attack.

- Fukui dual reactivity descriptor $\left(\Delta \mathrm{f}_{\mathrm{k}}\right)$, the dual local softness $\left(\Delta \mathrm{s}_{\mathrm{k}}\right)$ and the multiphilicity descriptors $\left(\Delta \omega_{\mathrm{k}}\right)$ reveal that the atoms $\mathrm{C} 8, \mathrm{C} 9$ and $\mathrm{S} 14$ are more favourable for nucleophilic attack while N1, S3, C2 and C7 are more favourable for electrophilic attack.

- High total first-order polarizability tensor $\alpha_{\text {total }}($ e.s.u $)=$ $57.1418 \times 10^{-24}$ reveals the possible inductive interactions in 2-mercaptobenzothiazole molecule.

- Total anisotropy of the polarizability (second-order term) $\beta_{0}($ e.s.u $)=19.4119 \times 10^{-28}$ characterize the electron acceptor properties of 2-mercaptobenzothiazole molecule.

\section{CONFLICT OF INTEREST}

The authors declare that there is no conflict of interests regarding the publication of this article.

\section{REFERENCES}

1. A.B. Sullivan, C.J. Hann and G.H. Kuhls, Rubber Chem. Technol., 65 , 488 (1992);

https://doi.org/10.5254/1.3538626.

2. M.R. Krejsa and J.L. Koenig, Rubber Chem. Technol., 66, 376 (1993); https://doi.org/10.5254/1.3538317.

3. M.H.S. Gradwell and W.J. McGill, J. Appl. Polym. Sci., 58, 2193 (1995); https://doi.org/10.1002/app.1995.070581206.

4. S. Bhoumick and S. Banerjee, Rubber Chem. Technol., 47, 251 (1974); https://doi.org/10.5254/1.3540435.

5. M.J. Frisch, G.W. Trucks, H.B. Schlegel, G.E. Scuseria, M.A. Robb, J.R. Cheeseman, G. Scalmani, V. Barone, B. Mennucci, G.A. Petersson, H. Nakatsuji, M. Caricato, X. Li, H.P. Hratchian, A.F. Izmaylov, J. Bloino, G. Zheng, J.L. Sonnenberg, M. Hada, M. Ehara, K. Toyota, R. Fukuda, J. Hasegawa, M. Ishida, T. Nakajima, Y. Honda, O. Kitao, H. Nakai, T. Vreven, J.A. Montgomery Jr., J.E. Peralta, F. Ogliaro, M. Bearpark, J.J. Heyd, E. Brothers, K.N. Kudin, V.N. Staroverov, R. Kobayashi, J. Normand, K. Raghavachari, A. Rendell, J.C. Burant, S.S. Iyengar, J. Tomasi, M. Cossi, N. Rega, J.M. Millam, M. Klene, J.E. Knox, J.B. Cross, V. Bakken, 
C. Adamo, J. Jaramillo, R. Gomperts, R.E. Stratmann, O. Yazyev, A.J. Austin, R. Cammi, C. Pomelli, J.W. Ochterski, R.L. Martin, K. Morokuma, V.G. Zakrzewski, G.A. Voth, P. Salvador, J.J. Dannenberg, S. Dapprich, A.D. Daniels, O. Farkas, J.B. Foresman, J.V. Ortiz, J. Cioslowski and D.J. Fox, Gaussian 09, Revision A.02, Gaussian, Inc., Wallingford CT (2009).

6. H.B. Schlegel, J. Comput. Chem., 3, 214 (1982); https://doi.org/10.1002/jcc.540030212.

7. P. Hohenberg and W. Kohn, Phys. Rev. B, 136, 864 (1964); https://doi.org/10.1103/PhysRev.136.B864.

8. A.D. Becke, J. Chem. Phys., 98, 5648 (1993); https://doi.org/10.1063/1.464913.

9. A.D. Becke, Phys. Rev. A, 38, 3098 (1988); https://doi.org/10.1103/PhysRevA.38.3098.

10. C. Lee, W. Yang and R.G. Parr, Phys. Rev. B, 37, 785 (1988); https://doi.org/10.1103/PhysRevB.37.785.

11. J.S. Murray and K. Sen, Molecular Electrostatic Potentials, Concepts and Applications, Elsevier, Amsterdam (1996).

12. C. Chidangil, M.K. Shukla and P.C. Mishra, Mol. Model. Annual, 4, 250 (1998); https://doi.org/10.1007/s008940050082.

13. R.I. Dennington, T. Keith and J. Millam, Gauss View, Version 5.0.8, Semichem. Inc., Shawnee Mission, KS (2008).

14. A.E. Reed and F. Weinhold, J. Chem. Phys., 83, 1736 (1985); https://doi.org/10.1063/1.449360.

15. A.E. Reed, R.B. Weinstock and F. Weinhold, J. Chem. Phys., 83, 735 (1985); https://doi.org/10.1063/1.449486.

16. A.E. Reed and F. Weinhold, J. Chem. Phys., 78, 4066 (1983); https://doi.org/10.1063/1.445134.

17. J.P. Foster and F. Weinhold, J. Am. Chem. Soc., 102, 7211 (1980); https://doi.org/10.1021/ja00544a007.

18. R.G. Parr and W. Yang, J. Am. Chem. Soc., 106, 4049 (1984); https://doi.org/10.1021/ja00326a036.
19. W. Yang and R.G. Parr, Proc. Natl. Acad. Sci. USA, 82, 6723 (1985); https://doi.org/10.1073/pnas.82.20.6723.

20. P.L. Polavarapu, J. Phys. Chem., 94, 8106 (1990); https://doi.org/10.1021/j100384a024.

21. M.F.C. Ladd and R.A. Palmer, Structure Determination by X-Ray Crystallography, Kluwer Academic/Plenum Publishers, N.Y., edn 4 (2003).

22. R. Franke, Theoretical Drug Design Methods, Elsevier: Amsterdam, pp 115-123 (1984).

23. K. Fukui, Theory of Orientation and Stereoselection; Springer-Verlag: New York, pp 34-39 (1975).

24. D.F.V. Lewis, C. Ioannides and D.V. Parke, Xenobiotica, 24, 401 (1994); https://doi.org/10.3109/00498259409043243.

25. Z. Zhou and R.G. Parr, J. Am. Chem. Soc., 112, 5720 (1990); https://doi.org/10.1021/ja00171a007.

26. R.G. Pearson, J. Org. Chem., 54, 1423 (1989); https://doi.org/10.1021/jo00267a034.

27. R.G. Parr and W. Yang, Density Functional Theory of Atoms and Molecules, Oxford University Press, Oxford (1989).

28. A. Cammarata, J. Med. Chem., 10, 525 (1967); https://doi.org/10.1021/im00316a004.

29. A. Leo, C. Hansch and C. Church, J. Med. Chem., 12, 766 (1969); https://doi.org/10.1021/jm00305a010.

30. R.G. Pearson, Chemical Hardness-Applications from Molecules to Solids, VCH Wiley, Weinheim (1997).

31. P. Geerlings, F. De Proft and W. Langenaeker, Chem. Rev., 103, 1793 (2003); https://doi.org/10.1021/cr990029p.

32. D.F.V. Lewis, J. Comput. Chem., 8, 1084 (1987); https://doi.org/10.1002/jcc.540080803.

33. J. Grunenberg and R. Herges, J. Chem. Inf. Comput. Sci., 35, 905 (1995); https://doi.org/10.1021/ci00027a018. 